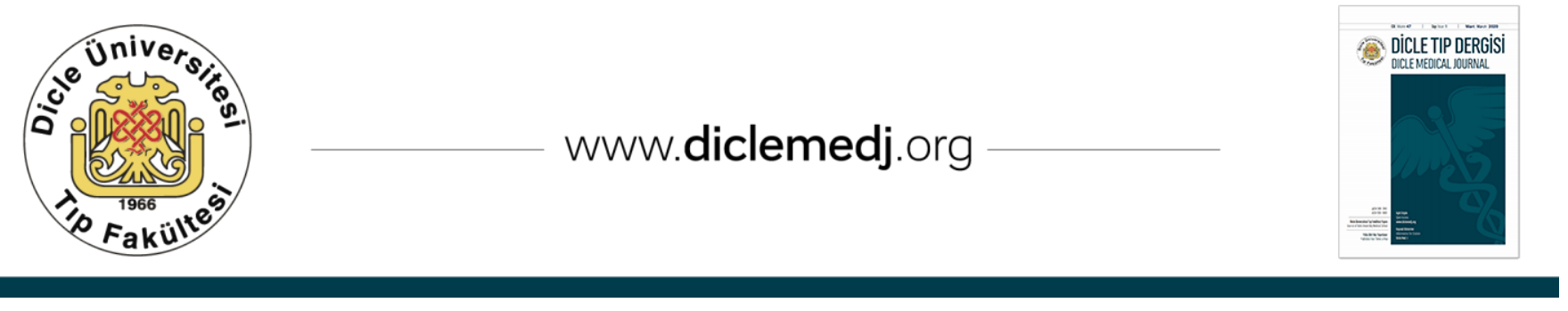

\title{
Yaş Tip Senil Maküla Dejeneresansı Olan Hastalarda İntravitreal Enjeksiyonun Okülokardiak Refleks Üzerine Etkisi
}

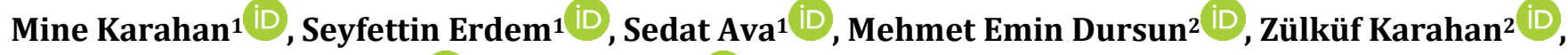 \\ Atılım Armağan Demirtaş3 ${ }^{\mathrm{iD}}$,Uğur Keklikçi1 ${ }^{\mathrm{iD}}$
}

1 Dicle Üniversitesi Tıp Fakültesi, Göz Hastalıkları A.D., Diyarbakır, Türkiye

2 Gazi Yaşargil Eğitim ve Araştırma Hastanesi, Diyarbakır, Türkiye

3 Tepecik Eğitim ve Araștırma Hastanesi, İzmir, Türkiye

Geliş: 31.12.2010; Revizyon: 07.02.2020; Kabul Tarihi: 11.02.2020

Öz

Amaç: Kliniğimizde yaş tip senil maküla dejeneresansı (SMD) olan hastalarda intravitreal enjeksiyonun (IVE) okülokardiak reflex (OKR) gelişimi ve kan basıncı değişikliklerine etkisini analiz etmeyi amaçladık.

Yöntemler: Nisan 2018 ile Eylül 2019 tarihleri arasında X kliniğinde IVE yapılan 55 hastanın dosyaları retrospektif olarak incelendi. Hastaların takip muayene bulguları ve demografik verileri incelenip kaydedildi. Hastaların enjeksiyon öncesi ve enjeksiyon sırasında sistolik ve diyastolik kan basıncı, kalp atım hızı ve ritim değişiklikleri kaydedildi.

Bulgular: Çalışmaya alınan 55 hastanın 30'unun $(\% 54,5)$ erkek, $25^{\prime}$ inin $(\% 45,5)$ ise kadın olduğunu saptadık. Hastalarda ortalama yaş $66.67 \pm 7.39(40-91)$ olarak saptandı. Hastaların 4'ünde $(\% 7,3)$ kalp atım hızında \%20 oranında düșüş izlenirken, 11'inde $(\% 20,0)$ kalp atım hızında \%10 oranında düşüş izlendi. $2(\% 3,6)$ hastada supraventiküler taşikardi gözlendi. Ortalama sistolik kan basıncında 129 mmHg'dan 133 mmHg'a arttığı izlenirken, ortalama diastolik kan basıncında 76 mmHg'dan 79 mmHg'a artmış olduğu izlendi. İVE'e bağlı olarak hastalarımızdan 5'inde (\%9) sistolik kan basıncının $180 \mathrm{mmHg}$ veya üzeri olduğu, 4 hastada $(\% 7,2)$ diastolik kan basıncının $110 \mathrm{mmHg}$ veya üzeri olduğu izlendi. Ortalama kalp hızının 85'ten 84'e düștüğü belirlendi.

Sonuç: Çalışmamızda ortalama kalp hızında azalma ile ortalama sistolik ve diastolik kan basıncında artış izlendi. İVE işlemi, kan basıncında geçici artış ile ilişkili olabileceği gibi OKR gelișimine sebep olabilmektedir. Bu değişiklikler tedavi sırasında kardiyovasküler veya serebrovasküler komplikasyonlar açısından risk faktörü oluşturabilir ve özellikle yüksek risk altındaki hastalarda önemli olabilir.

Anahtar kelimeler: İntravitreal enjeksiyon, okülokardiak refleks, senil maküla dejeneresansı

DOI: 10.5798/dicletip.706138

Yazıșma Adresi / Correspondence: Seyfettin Erdem, Dicle Üniversitesi Tıp Fakültesi, Göz Hastalıkları A.D.,21280, Diyarbakır, Türkiye e-mail:

serdem2147@hotmail.com 


\title{
The Effect Of Intravitreal Injecton On Oculocardiac Reflex In Patients With Wet-Type Senile Macular Degeneration
}

\begin{abstract}
Objective: We aimed to analyze the effect of intravitreal injection (IVI) on oculocardiac reflex (OCR) development and blood pressure changes in patients with age-type senile macular degeneration (SMD) in our clinic.

Methods: The records of 55 patients who underwent IVI at X Clinic between April 2018 and September 2019 were reviewed retrospectively. Demographic data of the patients were examined and recorded. Cystolic and diastolic blood pressure, heart rate and rhythm changes were recorded before and during the injection.

Results: We dedected that $30(54.5 \%)$ of 55 patients were male and $25(45.5 \%)$ were female. The mean age was $66.67 \pm$ $7.39(40-91)$ years. Heart rate decreased by $20 \%$ in 4 patients (7.3\%), while heart rate decreased by $10 \%$ in 11 patients (20.0\%). Supraventicular tachycardia was observed in 2 (3.6\%) patients. Mean systolic blood pressure increased from $129 \mathrm{mmHg}$ to $133 \mathrm{mmHg}$, while mean diastolic blood pressure increased from $76 \mathrm{mmHg}$ to $79 \mathrm{mmHg}$. Due to IVE, in 5 (9\%) of our patients, systolic blood pressure was $180 \mathrm{mmHg}$ or more, and in 4 patients (7.2\%) diastolic blood pressure was $110 \mathrm{mmHg}$ or more. Average heart rate was reduced from 85 to 84 .

Conclusions: We detected mean decrease in heart rate and an increase in mean systolic and diastolic blood pressure. IVI procedure may be associated with transient increase in blood pressure or may cause OCR development. These changes may be a risk factor for cardiovascular or cerebrovascular complications during treatment and may be particularly important in high-risk patients.
\end{abstract}

Keywords: Intravitreal injection, oculocardia reflex, senile macular degeneration.

\section{GİRIŞ}

Aschner refleksi veya trigeminovagal refleksi (TVR) olarak da bilinen OKR, ilk kez 1908 yılında göz küresi üzerindeki doğrudan basıya sekonder kalp hızındaki bir azalma olarak tanımlanmıştır. Glob basısını veya ekstraoküler kasların traksiyonunu takiben kalp hızındaki $\% 20$ 'den daha fazla azalma ile tanımlanır. Refleks en sık sinüs bradikardisi ile sonuçlanır. Ancak, azalmış arter basıncı, aritmi, asistol ve hatta kalp durması ile bildirilen bir ilişkisi vardır $^{1-3}$. OKR, genellikle göz dışı kasına uygulanan traksiyondan kaynaklanır. Refleksin afferent kolu trigeminal sinirin oftalmik dalıdır, efferent kolu ise sinoatriyal dügüm uyarılarını azaltan ve bunun sonucunda bradikardiya neden olan vagus siniridir ${ }^{4,5}$.

Lokal ve genel anestezi sırasında bu refleksin yansıması görülebilir. Oküler girişim, orbital dokunun ve ekstra oküler kasların (özellikle medial rektus kasının) traksiyonu, göz küresine basınç uygulanması; bulantı, senkop, kardiyak aritmi (bradikardi, nodal ritm, ventriküler disritmi) ve hatta asistoli ile sonuçlanabilir. Göz kapağının gerilmesi ve göze soğuk sıvı irrigasyonunda da benzer tablo görülebilir6 ${ }^{6}$.

OKR sonucu gelişen bradikardi genellikle uyarının sonlandırılmasıyla normale döner, fakat bradikardi ve kardiak depresyonun maksimum olduğu ilk birkaç saniyede kardiak arrest gelişebilir. $\mathrm{Bu}$ yüzden dikkatli monitorizasyon, cerrah ile sürekli diyalog, antikolinerjik ajanlar ve kardiak resisütasyon için gerekli tüm malzemeler bu refleksin gelişebilme ihtimali olan tüm girişimlerde hazır bulundurulması gerekir? .

Hastanın yaşı ve cinsiyeti, premedikasyon kullanımı, anestezi tekniği, ameliyat türü ve ameliyat edilen kasın sırası gibi bazı risk faktörlerinin OKR oluşumunu etkilediği gösterilmiştir. Bazı araştırmalar, kadın hastalarda OKR oluşumunun daha yüksek 
olduğunu göstermiștir, ancak OKR'li hastaların cinsiyetleri arasında bir fark olmadığını bildiren çalışmalar da vardır ${ }^{8,9}$.

Senil maküla dejeneresansı (SMD) yaşlı popülasyonda geriye dönüşümsüz körlügün önde gelen sebebidir. 2020 yılında 85 yaş üzerindeki popülasyonun \%100'ün üzerinde artacağı hesaplandığından bu hastalığın prevelansının dramatik olarak artış göstereceği düşünülmektedir ${ }^{10}$. Son ylllarda SMD tedavisinde gündemde olan tedavi protokolleri cerrahi tedavi ve cerrahi dışındaki tedaviler olarak ikiye ayrllabilir ${ }^{11}$.

Birçok çalışma, yüksek vasküler endotelyal growth faktör (VEGF) seviyesinin yaş tip SMD, diabetik retinopati gibi oküler neovasküler hastalıkların patogenezinde önemli olduğunu göstermiştir. Anti-VEGF tedavisi, çok sayıda retina hastalıklarını tedavi etmek için yaygın olarak kullanılır ve birkaç randomize klinik çalışmada güvenlik sinyalleri göstermemiştir ${ }^{12}$. VEGF'nin inaktivasyonu, artık yaş tip SMD tedavisi için belirlenmiş bir stratejidir. Normal fonksiyonları sürdürmek için gözde yeterli VEGF konsantrasyonları gerekse de, VEGF'nin aşırı üretimi zararlıdır ${ }^{13}$. Ranibizumab, tüm VEGF izoformlarının özellikle güçlü bir inhibitörü olacak şekilde tasarlanmıştır ${ }^{14}$.

Bu çalışmada kliniğimizde yaş tip SMD'si olan hastalarda intravitreal ranibizumab enjeksiyonun OKR gelişimi ve kan basıncı değişikliklerine etkisini analiz etmeyi amaçladık.

\section{YÖNTEMLER}

Nisan 2018 ile Eylül 2019 tarihleri arasında Diyarbakır Gazi Yaşargil Eğitim Araştırma Hastanesi Göz hastalıkları kliniğinde SMD nedeniyle IVE yapılan 55 hastanın dosyaları retrospektif olarak incelendi. Çalışma Gazi Yaşargil Eğitim ve Araştırma Hastanesi Etik Kurulu (2019/270 sayılı karar) tarafindan onaylanmış ve Helsinki Bildirgesi ilkelerine uygun olarak yürütülmüştür. Hastaların takip muayene bulguları ve demografik verileri incelenip kaydedildi. Hastaların enjeksiyon öncesi ve enjeksiyon sırasinda sistolik ve diastolik kan basıncı, kalp atım hızı ile ritm değişiklikleri kaydedildi.

\section{Cerrahi Yöntem}

Proparacaine HCI $(\% 0,5)$ ile (on dakikada en az $3 \mathrm{kez}$ ) topikal anestezi sağlanan hasta yatar pozisyonda müdahale masasına alındı. Hastanın TA ve kalp atım hızı ve ritm değişiklikleri kaydedildi. Göz ve ekleri batikon ile temizlendi. Steril oftalmik örtü örtülen hastaların göz kapağı blefarosta ile açıldı, konjoktival keseye sulandırılmış batikon damlatıldıktan $5 \mathrm{dk}$ sonra intravitreal ranibizumab enjeksiyonu yapıldı. İşlem sırasında sistolik ve diastolik tansiyon, kalp atım hızı ile ritm değiş̧iklikleri kaydedildi.

\section{İstatiksel Analiz}

Veri analizi yapmak için IBM SPSS Statistics yazılımı, sürüm 22 (IBM Corp, Chicago, Illinois, ABD) kullanıldı. Sürekli değişkenler ortalama \pm standart sapma, kategorik değişkenler ise frekans ve yüzde olarak bildirilmiştir. Tüm analizler için $\mathrm{P}<0.05$ anlamlı kabul edildi.

\section{BULGULAR}

Çalışmaya alınan 55 hastanın; 30'unun $(\% 54,5)$ erkek, 25'inin $(\% 45,5)$ ise kadın olduğunu saptadık. Hastalarda ortalama yaş $66.67 \pm 7.39$ (40-91) olarak saptandı. IVE yapılan hastaların $15^{\prime}$ inde $(\% 27,2)$ diabet, $20^{\prime}$ inde $(\% 36,3)$ hipertansiyon olduğu belirlendi.

Hastaların 4'ünde $(\% 7,3)$ kalp atım hızında $\% 20$ oranında düşüş izlenirken, 11'inde $(\% 20,0)$ kalp atım hızında \%10 oranında düşüş izlendi. 2 $(\% 3,6)$ hastada supraventiküler taşikardi gözlendi. Kadın ve erkekler arasında kalp atım hızı açısından fark izlenmedi. Ortalama sistolik kan basincında 129 mmHg'dan 133 mmHga arttığ 1 izlenirken, ortalama diastolik kan basıncında 76 mmHg'dan 79 mmHg'a artmış 
olduğu izlendi. Ortalama kalp hızının 85'ten 84 'e düştüğü belirlendi. IVE'e bağlı olarak hastalarımızdan 5'inde (\%9) sistolik kan basıncının $180 \mathrm{mmHg}$ veya üzeri olduğu, 4 hastada $(\% 7,2)$ diastolik kan basıncının $110 \mathrm{mmHg}$ veya üzeri olduğu izlendi. Ortalama kalp hızının 85'ten 84'e düștüğü belirlendi.

\section{TARTIŞMA}

Anti-VEGF ajanlarının sistemik VEGF'i bloke edebileceği ve bu nedenle potansiyel olarak tromboembolik olaylar, miyokard enfarktüsü, serebrovasküler inme, hipertansiyon gibi sistemik yan etkiler ile sonuçlanabileceği bildirilmiștir ${ }^{12,14}$. Bununla birlikte, perioperatif tansiyon yükselmesi gibi diğer faktörler, bu terapi sırasinda görülen advers olaylara potansiyel olarak katkıda bulunabilir ${ }^{15,16}$.

Berger ve ark. ameliyat öncesi yapılan ölçümlere kıyasla diyastolik ve sistolik kan basıncı ve nabız hızının, IVE sırasında belirgin şekilde yükseldiğini ve kan basıncındaki yükselişin çoğunun hastanın IVE prosedüründen önce hazırlanma aşamasından sonra meydana geldiğini tespit etmişlerdir ${ }^{17}$.

Özden ve ark. retrobulber anestezi ile gerçekleştiren katarakt ve şaşıllk hastalarında kalp ritim değişikliklerini incelemişlerdir. Yapılan çalışmada şaşılık hastalarında \%20 oranında bradikardi, katarakt hastalarında değişik dönemlerde \%38,8-83,2 oranında aritmi tespit etmişlerdir ${ }^{18}$.

Kayıkçığlu ve ark, subkonjonktival enjeksiyonlar sırasında özellikle bradikardi, supraventiküler taşikardi gibi ritim değişiklikleri olabileceğini gözlemledi, ancak hiçbiri acil müdahale gerektirecek kadar ciddi veya klinik olarak semptomatik değildi. Çalışma grubundaki $25(\% 47,2)$ hastada subkonjoktival enjeksiyona bağlı olarak OKR gözlendi. Bu çalışmada OKR saptanan ve saptanmayan hastalar kıyaslanmış OKR saptananların yaş olarak daha küçük olduğu saptanmış ancak cinsiyet, düşük ağrı seviyesi ve enjekte edilen ilaç tipinin OKR oluşumuyla ilişkisi bulunamamıștır ${ }^{19}$. Erakgün ve ark, retinal dekolman ya da submaküler hemoraji nedeniyle uygulanan intravitreal SF6 gaz enjeksiyonu sırasında hastaların \%46'sında, oküler masaj sırasında ise \%66'sında OKR geliştiğini bildirmişlerdir ${ }^{20}$.

Bizim çalışmamızda da OKR saptanan veya kan basıncında artış olan hiçbir hastada müdahale gerektirecek ölçüde ciddi derecede değişiklik izlenmedi. Basının azaltılması veya ortadan kaldırılmasıyla OKR'in düzeldiği gözlendi. OKR gelişimi açısından cinsiyet ve yaş farkının anlamlı olmadığı gözlendi.

Dornberger ve ark. 50 yaş üstü, hipertansiyon ve ilaç gerektiren kalp hastalıklarının OKR gelişimi açısından predispozan faktörler olarak bulmuşken, OKR gelişim sıklığının ise diyabetle azaldığını belirlemişlerdir ${ }^{20}$. Matarasso hafif anestezi altında opere edilen, kardiak hastalık öyküsü olan, genç anksiyeteli kadınlarda OKR eğiliminin daha yüksek olduğunu belirtmektedir ${ }^{22}$. Schaller ve ark. tarafından TVR kalp hizı ve ortalama kan basıncında başlangıç değerine göre $\% 20$ den fazla ani düşüş olarak tanımlanmıştır ${ }^{23}$.

Bizim çalışmamızda 55 hastanın 4'ünde $(\% 7,3)$ kalp atım hızında \%20 den fazla düşüş izlenirken, $11(\% 20)$ hastada \%10 oraninda kalp atım hızında azalma izlendi. 2 hastada supraventiküler taşikardi $(\% 3,6)$ gözlendi. Yine bizim çalışmamızda ortalama sistolik ve diastolik kan basıncında artış gözlendi. İntravitreal enjeksiyona bağlı olarak hastalarımızdan 5'inde (\%9) sistolik kan basıncının $180 \mathrm{mmHg}$ veya üzeri olduğu, 4 hastada $(\% 7,2)$ diastolik kan basıncinın 110 mmHg veya üzeri olduğu izlendi.

Bu refleksin ortaya çıkması, herhangi bir önemli işaret olmadan tehdit edici sonuçlarla ilişkili olabileceğinden, önlenmesi ve yönetimi, cerrah ve anestezi uzmanı için çok önemlidir. 
IVE işlemi, kan basıncında geçici artış ile ilişkili olabileceği gibi OKR gelişimine sebep olabilmektedir. Her ne kadar oluşan değişiklikler müdahale gerektirecek kadar ciddi sonuçlar doğurmamış olsa bile bu tedavi sırasında kardiyovasküler veya serebrovasküler komplikasyonlar açısından risk faktörü oluşturabilir ve özellikle yüksek risk altındaki hastalarda önemli olabilir. Kardiyovasküler veya serebrovasküler olaylar açısından risk altındaki hastalarda, perioperatif kan basıncı ve kalp ritm değişikliklerini izleme veya antihipertansif tedavi düşünülmelidir. Yapılacak işlemin olabildiğince ameliyathane koşullarında ya da en azından anestezi uzmanının olabileceği, antikolinerjik ajanların ve kardiak resisütasyon için gerekli tüm malzemelerin bulunduğu ortamda yapılmasının oluşabilecek komplikasyonların önlenmesi açısından önemli olduğunu düşünmekteyiz.

Etik Kurul Kararı: Çalışma Gazi Yaşargil Eğitim ve Araştırma Hastanesi Etik Kurulu (2019/270 sayılı karar) tarafından onaylanmış ve Helsinki Bildirgesi ilkelerine uygun olarak yürütülmüştür.

Çıkar Çatışması Beyanı: Yazarlar çıkar çatışması olmadığını bildirmişlerdir.

Finansal Destek: Bu çalışma her hangi bir fon tarafından desteklenmemiştir.

Declaration of Conflicting Interests: Theau thorsdeclare that theyhavenoconflict ofinterest.

Financial Disclosure: No financial support was received.

\section{KAYNAKLAR}

1. Waldschmidt B, Gordon N. Anesthesia for pediatric ophthalmologic surgery. J AAPOS [Internet]. 2019 Jun; 23: 127-31.

2. Dunphy L, Anand P. Paediatric orbital trapdoor fracture misdiagnosed as a head injury: A cautionary tale! BMJ Case Rep [Internet]. 2019 Apr 3; 12: e228739.

3. Arnold RW, Bond AN, McCall M, Lunoe L. The oculocardiac reflex and depth of anesthesia measured by brain wave. BMC Anesthesiol. 2019 Dec 14; 19: 36.

4. Alexander JP. Reflex disturbances of cardiac rhythm during ophthalmic surgery. $\mathrm{Br} J$ Ophthalmol. 1975 Sep 1; 59: 518-24.

5. Allen LE, Sudesh S, Sandramouli S, et al. The association between the oculocardiac reflex and post-operative vomiting in children undergoing strabismus surgery. Eye . 1998; 12: 193-6.

6. BOR C, ÇERTUĞ A. Oftalmik cerrahide anestezi. Ege Tıp Derg. 2015; 54: 46-53.

7. Ginsburg RN, Cartwright MJ, Murad SS, Nelson CC. Oculocardiac reflex in the anophthalmic socket. Ophthalmic Surg. 1992; 23: 135-7.

8. Apt L, Isenberg S, Gaffney WL. The oculocardiac reflex in strabismus surgery. Am J Ophthalmol. 1973; 76: 533-6.

9. Lai YH, Hsu HT, Wang HZ, Cheng KI, Wu KY. The oculocardiac reflex during strabismus surgery: Its relationship to preoperative clinical eye findings and subsequent postoperative emesis. J AAPOS. 2014; 18: 151-5.

10. Thylefors B. A global initiative for the elimination of avoidable blindness. Indian J Ophthalmol. 1998; 46: 129-30.

11. Hawkins BS, Fine SL, Donald J, Gass M. Argon Laser Photocoagulation for Neovascular Maculopathy: Three-year Results From Randomized Clinical Trials. Arch Ophthalmol. 1986; 104: 694-701.

12. Brown DM, Nguyen QD, Marcus DM, et al. Long-term outcomes of ranibizumab therapy for diabetic macular edema: The 36-month results from two phase III trials: RISE and RIDE. Ophthalmology. 2013 Oct; 120: 2013-22.

13. Ng EWM, Adamis AP. Targeting angiogenesis, the underlying disorder in 
neovascular age-related macular degeneration. Can J Ophthalmol. 2005 Jun; 40: 352-68.

14. Ferrara N, Damico L, Shams N, Lowman H, Kim R. Development of ranibizumab, an antivascular endothelial growth factor antigen binding fragment, as therapy for neovascular age-related macular degeneration. Retina. 2006; 26: 859-70. 2

15. Scappaticci FA, Skillings JR, Holden SN, , et al. Arterial thromboembolic events in patients with metastatic carcinoma treated with chemotherapy and bevacizumab. J Natl Cancer Inst. 2007; 99: 1232-9.

16. Huang H, Zheng Y, Zhu J, et al. An updated meta-analysis of fatal adverse events caused by bevacizumab therapy in cancer patients. Lafrenie R, editor. PLoS One. 2014; 9: e89960.

17. Berger V, Munk MR, Lersch $F$, et al. Association of Intravitreal Injections with Blood Pressure Increase: The Following Excitement and Anxiety Response under Intravitreal Injection Study. JAMA Ophthalmol. 2019; 137: 87-90.
18. Serap Özden, Ülkü Çeliker, Hüseyin Çeliker Na. Oküler Cerrahide Okülokardiak Refleks. Turkiye Klin J Ophthalmol. 1993; 2: 88-91.

19. Kayikçioğlu Ö, Kayikçioğlu M, Erakgün T, Güler C. Electrocardiographic changes during subconjunctival injections. Int Ophthalmol. 1999; 23: 37-41.

20. Erakgün T, Ünsal E, Eğrilmez S, menteș J, Akkın C. The Oculocardiac Reflex İn Intravitreal Gas Injection Under Topical Anesthesia. T.Oft.Gaz.2002: 32: 791-795.

21. Dornberger I, Quast D, Velhagen KH, Bellach J, Guckler A. The oculocardiac reflex during vitrectomy under neuroleptanalgesia. Anaesthesiol Reanim. 1991; 16: 94-106.

22. Matarasso A. The oculocardiac reflex in blepharoplasty surgery. Plast Reconstr Surg. 1989; 83: 243-8.

23. Schaller B, Probst R, Strebel S, Gratzl O. Trigeminocardiac reflex during surgery in the cerebellopontine angle. J Neurosurg. 1999; 90: 215-20. 